Journal of Mathematics and Statistics 2 (4): 445-452, 2006

ISSN 1549-3644

(C) 2006 Science Publications

\title{
A Mean-Variance Portfolio Optimal Under Utility Pricing
}

\author{
Hürlimann Werner \\ Feldstrasse 145, CH-8004 Zürich, Switzerland
}

\begin{abstract}
An expected utility model of asset choice, which takes into account asset pricing, is considered. The obtained portfolio selection problem under utility pricing is solved under several assumptions including quadratic utility, exponential utility and multivariate symmetric elliptical returns. The obtained unique solution, called optimal utility portfolio, is shown mean-variance efficient in the classical sense. Various questions, including conditions for complete diversification and the behavior of the optimal portfolio under univariate and multivariate ordering of risks as well as riskadjusted performance measurement, are discussed.
\end{abstract}

Key words: Portfolio selection, utility pricing, mean-variance efficiency, elliptical distributions

\section{INTRODUCTION}

The mean-variance model of asset choice by Markowitz $^{[1]}$ is one of the cornerstone of modern finance. Despite its shortcomings and restrictions (multivariate normal returns for arbitrary preferences or quadratic utility for arbitrary distributions) this fundamental model remains popular, mainly due to its analytical tractability and its rich empirical implications.

In the present study, we consider a model of portfolio selection, which takes into account asset pricing. As usual, the goal is maximization of expected utility of the investor's terminal random wealth. However, as side constraint, we suppose that asset prices are determined by the utility principle, which expresses the indifference between the future random value and its certainty equivalent. The analysis is restricted to the case where all assets are risky. This assumption is most useful for strategic asset allocation, where even money markets are considered risky investments.

Our portfolio selection problem under utility pricing is defined in Section 2 and solved under several alternative assumptions. In Section 2.1, we assume quadratic utility functions but arbitrary returns and obtain the optimal quadratic utility portfolio. Assuming multivariate normally distributed returns and an exponential utility function in Section 2.2, the solution is called optimal exponential utility portfolio. The solution in Section 2.3, obtained for multivariate symmetric elliptical returns but arbitrary left truncated utility functions, is called optimal elliptical portfolio. As a remarkable main result, we show in Theorem 3.1 that the three derived optimal utility portfolios define a unique optimal utility portfolio, which is mean-variance efficient in the classical sense. In Section 4, we study the behavior of this portfolio with respect to some typical situations. The conditions for complete diversification are stated. Then, we discuss the behavior of the optimal portfolio under univariate and multivariate ordering of risks as well as under riskadjusted performance measurement.

2. Portfolio selection under utility pricing: Consider the portfolio selection over a static one-period in an economy with a finite set $n$ of risky assets, which has the following characteristics:

$\mathrm{S}$ : initial investment amount

$R_{j}$ : random return on the $j$-th risky asset, $\mathrm{j}=1, \ldots, \mathrm{n}$

$W_{j}$ : proportion of initial amount invested in the $j$-th risky asset, $\mathrm{j}=1, \ldots, \mathrm{n}$

$P_{j} \quad$ : initial price of the $j$-th risky asset, $\mathrm{j}=1, \ldots, \mathrm{n}$

Let $\mathrm{S}_{\mathrm{j}}=\mathrm{w}_{\mathrm{j}} \cdot \mathrm{S}$ be the initial amount invested in the $j$-th risky asset such that $\sum_{j=1}^{n} S_{j}=S$. Define the proportion $\lambda_{\mathrm{j}}$ of shares of the $j$-th risky asset by the condition $\lambda_{\mathrm{j}} \mathrm{P}_{\mathrm{j}}=\mathrm{S}_{\mathrm{j}}, \quad \mathrm{j}=1, \ldots, \mathrm{n}$.

We suppose that the initial prices of the risky assets are utility prices. For this, let be given non-decreasing and concave utility functions $u_{j}(x), j=1, \ldots, n$, one for each risky asset. The utility principle determines prices in such a way that there is indifference between receiving the future random value $P_{j} \cdot\left(1+R_{j}\right)$ and its corresponding certainty equivalent $P_{j}$, that is prices solve the system of equations

$u\left(P_{j}\right)=E\left[u\left(P_{j} \cdot\left(1+R_{j}\right)\right)\right], \quad j=1, \ldots, n$.

Using these prices, the one-period increase in wealth or random gain of a portfolio choice $\lambda=\left(\lambda_{1}, \ldots, \lambda_{\mathrm{n}}\right)$ is given by

$\mathrm{G}(\lambda)=\sum_{\mathrm{j}=1}^{\mathrm{n}} \lambda_{\mathrm{j}} \mathrm{P}_{\mathrm{j}} \mathrm{R}_{\mathrm{j}}$

Corresponding Author: $\quad$ Hürlimann Werner, Feldstrasse 145, CH-8004 Zürich, Switzerland 
Suppose an investor uses a non-decreasing and concave utility function $u(x)$. Then, the portfolio selection problem of the investor consists to maximize the expected utility of the terminal random wealth $\varphi(\lambda)=\mathrm{E}[\mathrm{u}(\mathrm{S}+\mathrm{G}(\lambda))]$ under the conditions (2.2).

In the next three Subsections three typical situations are considered. We begin with the two wellknown mean-variance legitimated cases of quadratic utility and multivariate normal returns and extend the latter to the case of multivariate symmetric elliptical returns.

2.1. Quadratic utility functions: Consider first quadratic utility functions $u_{j}(x)=u(x)=x-\frac{1}{2} \gamma x^{2}, j=1, \ldots, n \quad$. The marginal utility $\mathrm{u}^{\prime}(\mathrm{x})=1-\gamma \mathrm{x}$ is non-negative provided $\mathrm{x} \leq \gamma^{-1}$, hence satiation is reached when $x \geq \gamma^{-1}$. To avoid this, one assumes that rates of return and initial wealth are such that satiation will not be attained ${ }^{[2]}$.

Solving (2.2) yields the quadratic utility prices

$\mathrm{P}_{\mathrm{j}}=\frac{1}{\gamma} \cdot \frac{1}{1+\frac{1}{2}\left(1+\mathrm{k}_{\mathrm{j}}^{2}\right) \mu_{\mathrm{j}}}, \quad \mathrm{j}=1, \ldots, \mathrm{n}$,

where $\mu_{\mathrm{j}}, \mathrm{k}_{\mathrm{j}}$ are the means and coefficients of variation of $\mathrm{R}_{\mathrm{j}}, \mathrm{j}=1, \ldots, \mathrm{n}$. To maximize $\varphi(\lambda)$ it suffices to solve the first order conditions

$\frac{\partial \varphi(\lambda)}{\partial \lambda_{1}}=P_{i} \cdot E\left[R_{i} \cdot u^{\prime}(S+G(\lambda))\right]=0, \quad i=1, \ldots, n$.

Under the assumption of a quadratic utility function, one obtains the equivalent conditions

$$
\frac{\gamma}{1-\gamma \mathrm{S}} \cdot \sum_{\mathrm{j}=1}^{\mathrm{n}} \lambda_{\mathrm{j}} \mathrm{P}_{\mathrm{j}} \cdot\left(\operatorname{Cov}\left[\mathrm{R}_{\mathrm{i}}, \mathrm{R}_{\mathrm{j}}\right]+\mu_{\mathrm{i}} \mu_{\mathrm{j}}\right)=\mu_{\mathrm{i}}, \quad \mathrm{i}=1, \ldots, \mathrm{n}
$$

Let $\mathrm{e}=\left(\mu_{1}, \ldots, \mu_{\mathrm{n}}\right)$ be the vector of expected returns and let $\vee^{\circ}=\left(\operatorname{Cov}\left[\mathrm{R}_{\mathrm{i}}, \mathrm{R}_{\mathrm{j}}\right]+\mu_{\mathrm{i}} \mu_{\mathrm{j}}\right)=\left(\mathrm{E}\left[\mathrm{R}_{\mathrm{i}} \mathrm{R}_{\mathrm{j}}\right]\right)$ be the matrix of second order moments, whose inverse is assumed to exist. Then (2.6) has the solution

$\frac{\gamma}{1-\gamma \mathrm{S}} \cdot \lambda_{\mathrm{j}} \mathrm{P}_{\mathrm{j}}=\left(\mathrm{V}^{\mathrm{o}} \mathrm{\sigma}^{1} \mathrm{e}\right)_{\mathrm{j}}, \quad \mathrm{j}=1, \ldots, \mathrm{n}$.

It follows that the optimal weight vector $\mathrm{w}^{0}=\left(\mathrm{w}_{1}, \ldots, \mathrm{w}_{\mathrm{n}}\right)$, with

$\mathrm{w}_{\mathrm{i}}^{\mathrm{o}}=\frac{\lambda_{\mathrm{i}} \mathrm{P}_{\mathrm{i}}}{\sum \lambda_{\mathrm{j}} \mathrm{P}_{\mathrm{j}}}, \quad \mathrm{i}=1, \ldots, \mathrm{n}$,

satisfies the simple relationship $\mathrm{w}^{\mathrm{o}}=\frac{\stackrel{\wp}{\sigma^{1} \mathrm{e}}}{\AA^{0}}$, with $\AA^{0}=\overline{1}^{\mathrm{T}} \cdot\left(\wp^{\circ} \sigma^{1} \mathrm{e}\right)$,

Where $\overline{1}=(1, \ldots, 1)$ denotes a vector of ones. The solution (2.9) defines the optimal quadratic utility portfolio. Furthermore, one has using (2.7) that

$$
\frac{\gamma \mathrm{S}}{1-\gamma \mathrm{S}}=\frac{\gamma}{1-\gamma \mathrm{S}} \cdot \sum \lambda_{\mathrm{j}} \mathrm{P}_{\mathrm{j}}=\AA^{\circ}, \text { that is } \gamma=\frac{\AA^{\circ}}{1+\AA^{\circ}} \cdot \frac{1}{\mathrm{~S}}
$$

Inserting (2.10) into (2.4) one obtains the quadratic utility prices

$\mathrm{P}_{\mathrm{j}}=\frac{1}{1+\frac{1}{2}\left(1+\mathrm{k}_{\mathrm{j}}^{2}\right) \mu_{\mathrm{j}}} \cdot \frac{1+\AA_{0}}{\AA^{0}} \cdot \mathrm{S}, \quad \mathrm{j}=1, \ldots, \mathrm{n}$.

The optimal quadratic utility proportions defined in (2.1) are then given by

$\left.\lambda_{\mathrm{j}}^{\mathrm{o}}=\frac{\mathrm{w}_{\mathrm{j}}^{\mathrm{o}}}{\mathrm{P}_{\mathrm{j}}} \cdot \mathrm{S}=\frac{1+\frac{1}{2}\left(1+\mathrm{k}_{\mathrm{j}}^{2}\right) \mu_{\mathrm{j}}}{1+\mathrm{K}^{\mathrm{o}}} \cdot\left(\mathrm{V}^{\mathrm{o}} \mathrm{e}\right)\right)_{\mathrm{j}}, \quad \mathrm{j}=1, \ldots, \mathrm{n}$

2.2. Multivariate normal returns and exponential utility: Another important situation, which allows for explicit analytical formulas, is a multivariate normal distribution of returns and exponential utility functions $\mathrm{u}_{\mathrm{j}}(\mathrm{x})=\mathrm{u}(\mathrm{x})=\frac{1}{\gamma}\left(1-\mathrm{e}^{-\gamma \cdot \mathrm{x}}\right), \quad \mathrm{j}=1, \ldots, \mathrm{n}, \quad$ with $\quad \gamma \quad$ the coefficient of risk aversion. Again, denote by $\mu_{\mathrm{j}}, \mathrm{k}_{\mathrm{j}}$ the means and coefficients of variation of $R_{j}, j=1, \ldots, n$.

Solving (2.2) yields the exponential utility prices

$\mathrm{P}_{\mathrm{j}}=\frac{1}{\gamma} \cdot \frac{1}{\frac{1}{2} \mathrm{k}_{\mathrm{j}}^{2} \mu_{\mathrm{j}}}, \quad \mathrm{j}=1, \ldots, \mathrm{n}$.

Since $\left(\mathrm{R}_{\mathrm{i}}, \mathrm{S}+\mathrm{G}(\lambda)\right)$ is bivariate normal, the application of Stein's Lemma yields $\operatorname{Cov}\left[\mathrm{R}_{\mathrm{i}}, \mathrm{u}^{\prime}(\mathrm{S}+\mathrm{G}(\lambda))\right]$

$=E\left[u^{\prime \prime}(S+G(\lambda))\right] \cdot \operatorname{Cov}\left[R_{i}, G(\lambda)\right], i=1, \ldots, n$.

(as (A.6) in Appendix). It follows that (2.5) is equivalent to the conditions

$\gamma \cdot \sum_{\mathrm{j}=1}^{\mathrm{n}} \lambda_{\mathrm{j}} \mathrm{P}_{\mathrm{j}} \cdot \operatorname{Cov}\left[\mathrm{R}_{\mathrm{i}}, \mathrm{R}_{\mathrm{j}}\right]=\mu_{\mathrm{i}}, \quad \mathrm{i}=1, \ldots, \mathrm{n}$.

Denote by $\mathrm{V}=\left(\operatorname{Cov}\left[\mathrm{R}_{\mathrm{i}}, \mathrm{R}_{\mathrm{j}}\right]\right)$ the covariance matrix, whose inverse is assumed to exist. Then (2.14) has the solution

$\gamma \cdot \lambda_{\mathrm{j}} \mathrm{P}_{\mathrm{j}}=\left(\mathrm{V}^{-1} \mathrm{e}\right)_{\mathrm{j}}, \quad \mathrm{j}=1, \ldots, \mathrm{n}$.

The optimal weight vector $\mathrm{w}^{0}=\left(\mathrm{w}_{1}, \ldots, \mathrm{w}_{\mathrm{n}}\right)$ is given by

$\mathrm{w}^{\mathrm{o}}=\frac{\mathrm{V}^{-1} \mathrm{e}}{\mathrm{A}}$, with $\mathrm{A}=\overline{1}^{\mathrm{T}} \cdot\left(\mathrm{V}^{-1} \mathrm{e}\right)$,

and defines the optimal exponential utility portfolio. With (2.15) one has $\gamma \mathrm{S}=\gamma \cdot \sum \lambda_{\mathrm{j}} \mathrm{P}_{\mathrm{j}}=\mathrm{A}$, hence $\gamma=\mathrm{A} \cdot \mathrm{S}^{-1}$. Inserted into (2.13) yields the exponential utility prices $\mathrm{P}_{\mathrm{j}}=\frac{1}{\frac{1}{2} \mathrm{k}_{\mathrm{j}}^{2} \mu_{\mathrm{j}}} \cdot \frac{\mathrm{S}}{\mathrm{A}}, \quad \mathrm{j}=1, \ldots, \mathrm{n}$.

The optimal exponential utility proportions (2.1) are then given by

$\lambda_{\mathrm{j}}^{\mathrm{o}}=\frac{\mathrm{w}_{\mathrm{j}}^{\mathrm{o}}}{\mathrm{P}_{\mathrm{j}}} \cdot \mathrm{S}=\frac{1}{2} \mathrm{k}_{\mathrm{j}}^{2} \mu_{\mathrm{j}} \cdot\left(\mathrm{V}^{-1} \mathrm{e}\right)_{\mathrm{j}}, \quad \mathrm{j}=1, \ldots, \mathrm{n}$

2.3. Multivariate elliptical returns and left truncated utility: Suppose that the random vector of returns $\left(\mathrm{R}_{1}, \ldots, \mathrm{R}_{\mathrm{n}}\right)$ follows a multivariate symmetric elliptical density of returns with mean $e$ and positive definite covariance matrix $V$ given by 
$f(x)=\frac{1}{\sqrt{\operatorname{det}(V)}} \cdot g\left[(x-e)^{\mathrm{T}} V^{-1}(x-e)\right]$

Where $\mathrm{g}:[0, \infty) \rightarrow[0, \infty)$ is some appropriate generator function. The non-decreasing almost everywhere differentiable concave utility function of the investor is assumed to take non-negative values such that $\mathrm{u}(\mathrm{x})=0$ for all $x \leq \lambda$. The constant 1 is chosen such that the utility associated to undesirable negative portfolio returns vanishes (see the examples below for illustration). Applying Fang et al. ${ }^{[3]}$, Theorem 2.16, p. 43 and Theorem 2.18, p. 45, one notes that $\left(\mathrm{R}_{\mathrm{i}}, \mathrm{S}+\mathrm{G}(\lambda)\right)$ is bivariate elliptical and satisfies the linear regression property required in Theorem A. 1 of the Appendix. Since $u(x)=0$ for $\mathrm{x} \leq 1$, the variant (A.1) of Stein's Lemma yields the relationship

$\operatorname{Cov}\left[\mathrm{R}_{\mathrm{i}}, \mathrm{u}^{\prime}(\mathrm{S}+\mathrm{G}(\lambda))\right]$

$=\frac{\operatorname{Cov}\left[\mathrm{G}(\lambda), \mathrm{u}^{\prime}(\mathrm{S}+\mathrm{G}(\lambda))\right]}{\operatorname{Var}[\mathrm{G}(\lambda)]} \cdot \operatorname{Cov}\left[\mathrm{R}_{\mathrm{i}}, \mathrm{G}(\lambda)\right], \mathrm{i}=1, \ldots, \mathrm{n}$.

It follows that (2.5) is equivalent to the system of equations

$$
\begin{aligned}
& -\frac{\operatorname{Cov}\left[\mathrm{G}(\lambda), \mathrm{u}^{\prime}(\mathrm{S}+\mathrm{G}(\lambda))\right]}{\operatorname{Var}[\mathrm{G}(\lambda)] \cdot \mathrm{E}\left[\mathrm{u}^{\prime}(\mathrm{S}+\mathrm{G}(\lambda))\right]} . \\
& \sum_{\mathrm{j}=1}^{\mathrm{n}} \lambda_{\mathrm{j}} \mathrm{P}_{\mathrm{j}} \operatorname{Cov}\left[\mathrm{R}_{\mathrm{i}}, \mathrm{R}_{\mathrm{j}}\right]=\mu_{\mathrm{i}}, \quad \mathrm{i}=1, \ldots, \mathrm{n}
\end{aligned}
$$

which has the solution

$$
\lambda_{\mathrm{j}} \mathrm{P}_{\mathrm{j}}=-\frac{\operatorname{Var}[\mathrm{G}(\lambda)] \cdot \mathrm{E}\left[\mathrm{u}^{\prime}(\mathrm{S}+\mathrm{G}(\lambda))\right]}{\operatorname{Cov}\left[\mathrm{G}(\lambda), \mathrm{u}^{\prime}(\mathrm{S}+\mathrm{G}(\lambda))\right]} \cdot\left(\mathrm{V}^{-1} \mathrm{e}\right)_{\mathrm{j}}, \mathrm{j}=1, \ldots, \mathrm{n}
$$

The optimal weight vector (2.8) is given by

$$
\mathrm{w}^{\mathrm{o}}=\frac{\mathrm{V}^{-1} \mathrm{e}}{\mathrm{A}} \text {, with } \mathrm{A}=\overline{1}^{\mathrm{T}} \cdot\left(\mathrm{V}^{-1} \mathrm{e}\right) \text {, }
$$

and defines the optimal elliptical portfolio. By (2.16) this coincides with the optimal exponential utility portfolio.

To illustrate, we assume in the examples below left truncated exponential utility functions such that for $\mathrm{j}=1, \ldots, \mathrm{n}$ one sets

$$
u_{j}(x)=\left\{\begin{array}{l}
0, \quad x \leq P_{j}\left(1+\mu_{j}\right), \\
\gamma^{-1} \cdot\left(1-\exp \left\{-\gamma\left[x-P_{j}\left(1+\mu_{j}\right)\right]\right\}\right), x \geq P_{j}\left(1+\mu_{j}\right),
\end{array}\right.
$$

and

$$
\mathrm{u}(\mathrm{x})=\left\{\begin{array}{l}
0, \quad \mathrm{x} \leq \mathrm{S}(1+\mu), \\
\gamma^{-1} \cdot(1-\exp \{-\gamma[\mathrm{x}-\mathrm{S}(1+\mu)]\}), \quad \mathrm{x} \geq \mathrm{S}(1+\mu),
\end{array}\right.
$$

where $\mu=\mathrm{E}\left[\mathrm{S}^{-1} \mathrm{G}(\lambda)\right]$ is the mean expected return of the portfolio. The special choice of the left truncation models the fact that returns below average are associated a zero utility. This might be appropriate for the design of optimal portfolios, whose goal is to "beat the market". In this situation, the pricing equations (2.2) are equivalent to

$$
\begin{aligned}
& E\left[\exp \left(-\gamma \mathrm{P}_{\mathrm{j}} \mathrm{R}_{\mathrm{j}}\right) \cdot 1_{\left\{\mathrm{R}_{\mathrm{j}} \geq \mu_{\mathrm{j}}\right\}}\right] \\
& =1-\frac{1}{2} \exp \left(-\gamma \mathrm{P}_{\mathrm{j}} \mu_{\mathrm{j}}\right), \quad \mathrm{j}=1, \ldots, \mathrm{n}
\end{aligned}
$$

where use has been made of $\operatorname{Pr}\left(\mathrm{R}_{\mathrm{j}} \leq \mu_{\mathrm{j}}\right)=\frac{1}{2}$ (symmetric margins).

Example 2.1: Normal inverted gamma returns

It appears instructive to illustrate our results with a non-trivial but tractable multivariate elliptical distribution, which finds wide interest in both Insurance and Finance. The mixture of a normal with inverted gamma variance yields the Pearson type VII distribution or generalised Student $\mathrm{t}^{[4-6]}$. It has been proposed to model financial returns by Praetz ${ }^{[7]}$, Blattberg and Gonedes ${ }^{[8]}$, Kon ${ }^{[9]}$, Taylor ${ }^{[10]}$, Hürlimann ${ }^{[11,12]}$. An actuarial application is found in Hürlimann $^{[13]}$. The multivariate density

$$
\begin{gathered}
\mathrm{f}(\mathrm{x})=\frac{\left[1+(\mathrm{x}-\mathrm{e})^{\mathrm{T}} \cdot \mathrm{C}^{-1} \cdot(\mathrm{x}-\mathrm{e})\right]^{-\left(\beta+\frac{\mathrm{n}}{2}\right)}}{\mathrm{B}\left(\beta, \frac{\mathrm{n}}{2}\right) \cdot \sqrt{\operatorname{det}(\mathrm{C})}}, \\
\mathrm{B}\left(\beta, \frac{\mathrm{n}}{2}\right)=\frac{\pi^{\frac{\mathrm{n}}{2}} \cdot \Gamma(\beta)}{\Gamma\left(\beta+\frac{\mathrm{n}}{2}\right)}, \beta>0,
\end{gathered}
$$

has location-scaled transformed Pearson VII marginal densities

$$
\begin{aligned}
& \mathrm{f}_{\mathrm{i}}(\mathrm{x})=\mathrm{B}\left(\beta, \frac{1}{2}\right)^{-1} \frac{1}{\mathrm{c}_{\mathrm{ii}}} . \\
& {\left[1+\left(\frac{\mathrm{x}-\mu_{\mathrm{i}}}{\mathrm{c}_{\mathrm{ii}}}\right)^{2}\right]^{-\left(\beta+\frac{1}{2}\right)}, \quad \mathrm{i}=1, \ldots, \mathrm{n}}
\end{aligned}
$$

If $\beta>1$ the variance $\sigma_{i}^{2}=\operatorname{Var}\left[R_{i}\right]$ exists and one has $\mathrm{c}_{\mathrm{ii}}=\sqrt{2(\beta-1)} \cdot \sigma_{\mathrm{i}}$. If $\beta=\frac{v}{2}, v=1,2,3, \ldots$, one recovers a location-scale transformed Student $\mathrm{t}$ with $v$ degrees of freedom. In particular $\beta=\frac{1}{2}$ is a Cauchy and $\beta=1$ is a Bowers distribution. If $\beta \rightarrow \infty$ the random variable $\sqrt{2(\beta-1)} \cdot\left(\mathrm{R}_{\mathrm{i}}-\mu_{\mathrm{i}}\right) \cdot \mathrm{c}_{\mathrm{ii}}^{-1}$ converges to a standard normal random variable. On the other hand, any linear combination $\mathrm{R}=\mathrm{w}^{\mathrm{T}} \cdot\left(\mathrm{R}_{1}, \ldots, \mathrm{R}_{\mathrm{n}}\right)$ has density

$\mathrm{f}_{\mathrm{R}}(\mathrm{x})=\mathrm{B}\left(\beta, \frac{1}{2}\right)^{-1} \frac{1}{\mathrm{c}} \cdot\left[1+\left(\frac{\mathrm{x}-\mu}{\mathrm{c}}\right)^{2}\right]^{-\left(\beta+\frac{1}{2}\right)}$,

with $\mu=\mathrm{w}^{\mathrm{T}} \cdot \mathrm{e}$ and $\mathrm{c}=\mathrm{w}^{\mathrm{T}} \cdot \mathrm{C} \cdot \mathrm{w}^{[3]}$, Theorem 2.16). The analytical formulas below use the special integral function

$\mathrm{I}(\mathrm{a}, \mathrm{b})=\int_{0}^{\infty}\left(1+\mathrm{x}^{2}\right)^{-\mathrm{a}} \mathrm{e}^{-\mathrm{bx}} \mathrm{dx}$,

whose computational evaluation is discussed in the Appendix B.

Under the assumption $\beta>1$ (variances are finite), one obtains after some calculation the formulas

$\mathrm{E}\left[\mathrm{u}^{\prime}(\mathrm{S}+\mathrm{G}(\lambda))\right]=\mathrm{B}\left(\beta ; \frac{1}{2}\right)^{-1} \cdot \mathrm{I}\left(\beta+\frac{1}{2}, \gamma \mathrm{Sc}\right)$,

$\operatorname{Cov}\left[\mathrm{G}(\lambda), \mathrm{u}^{\prime}(\mathrm{S}+\mathrm{G}(\lambda))\right]=-\gamma \cdot \operatorname{Var}[\mathrm{G}(\lambda)]$.

$\left(\frac{2 \beta-2}{2 \beta-1}\right) \cdot \mathrm{B}\left(\beta ; \frac{1}{2}\right)^{-1} \cdot \mathrm{I}\left(\beta-\frac{1}{2}, \gamma \mathrm{Sc}\right)$,

which inserted into (2.22) yield the relationships 
$\lambda_{\mathrm{j}} \mathrm{P}_{\mathrm{j}}=\frac{1}{\gamma} \cdot\left(\frac{2 \beta-1}{2 \beta-2}\right) \cdot \frac{\mathrm{I}\left(\beta+\frac{1}{2}, \gamma \mathrm{Sc}\right)}{\mathrm{I}\left(\beta-\frac{1}{2}, \gamma \mathrm{Sc}\right)}$

$\left(\mathrm{V}^{-1} \mathrm{e}\right)_{\mathrm{j}}, \quad \mathrm{j}=1, \ldots, \mathrm{n}$

A similar calculation shows that the utility pricing equations (2.26) are equivalent to

$\mathrm{B}\left(\beta ; \frac{1}{2}\right)^{-1} \cdot \exp \left(-\gamma \mathrm{P}_{\mathrm{j}} \mu_{\mathrm{j}}\right) \cdot \mathrm{I}\left(\beta+\frac{1}{2}, \gamma \mathrm{Sc}\right)$

$=1-\frac{1}{2} \exp \left(-\gamma \mathrm{P}_{\mathrm{j}} \mu_{\mathrm{j}}\right), \quad \mathrm{j}=1, \ldots, \mathrm{n}$

Using (2.32) and $\mathrm{S}=\sum \lambda_{\mathrm{j}} \mathrm{P}_{\mathrm{j}}$ one sees that

$\gamma \mathrm{S}=\left(\frac{2 \beta-1}{2 \beta-2}\right) \cdot \frac{\mathrm{I}\left(\beta+\frac{1}{2}, \gamma \mathrm{Sc}\right)}{\mathrm{I}\left(\beta-\frac{1}{2}, \gamma \mathrm{Sc}\right)} \cdot \mathrm{A}$

Which is an implicit equation for the parameter $\gamma$. Inserting its numerical value into (2.33) it is possible to determine numerically the corresponding truncated exponential utility prices and the optimal proportions defined in (2.1).

\section{Example 2.2: Symmetric Kotz type returns}

Another tractable family of symmetric elliptical distributions has the density

$$
\begin{aligned}
& f(x)=\frac{K_{n}}{\sqrt{\operatorname{det}(C)}}\left[(x-e)^{T} C^{-1}(x-e)\right]^{N-1} \cdot \exp \left\{r\left[(x-e)^{T} C^{-1}(x-e)\right]^{s}\right\}, \\
& r, s>0, \quad 2 N+n>0
\end{aligned}
$$

with the normalizing constant

$$
\mathrm{K}_{\mathrm{n}}=\frac{\mathrm{s} \cdot \Gamma\left(\frac{\mathrm{n}}{2}\right)}{\pi^{\frac{\mathrm{n}}{2}} \cdot \Gamma\left(\frac{2 \mathrm{~N}+\mathrm{n}-2}{2 \mathrm{~s}}\right)} \cdot \mathrm{r}^{\frac{2 \mathrm{~N}+\mathrm{n}-2}{2 \mathrm{~s}}}
$$

This family, introduced by $\mathrm{Kotz}^{[14]}$, is called symmetric Kotz type distribution in Fang et al. ${ }^{[3]}$. It reduces to the multivariate normal distribution in case $\mathrm{N}=\mathrm{s}=1, \quad \mathrm{r}=\frac{1}{2}$. The marginal densities take the form

$$
f_{i}(x)=\frac{K_{1}}{c_{i}} \cdot\left(\frac{x-\mu_{i}}{c_{i}}\right)^{2(N-1)} \cdot \exp \left\{-r\left(\frac{x-\mu_{i}}{c_{i}}\right)^{2 s}\right\}
$$

and the portfolio return is again of symmetric Kotz type such that

$$
\mathrm{f}_{\mathrm{R}}(\mathrm{x})=\frac{\mathrm{K}_{1}}{\mathrm{c}} \cdot\left(\frac{\mathrm{x}-\mu}{\mathrm{c}}\right)^{2(\mathrm{~N}-1)} \cdot \exp \left\{-\mathrm{r}\left(\frac{\mathrm{x}-\mu}{\mathrm{c}}\right)^{2 \mathrm{~s}}\right\}
$$

Analytical evaluation requires the following special integral function

$J(a, b, r, s)=\frac{1}{b} \cdot \int_{0}^{\infty} x^{a} e^{-r x^{2 s}-b x} d x$

whose computational evaluation is provided in the Appendix B. A straightforward calculation yields the formulas

$$
\begin{aligned}
& \mathrm{E}\left[\mathrm{u}^{\prime}(\mathrm{S}+\mathrm{G}(\lambda))\right]=\mathrm{K}_{1} \gamma \mathrm{Sc} \cdot \mathrm{J}(2(\mathrm{~N}-1), \gamma \mathrm{Sc}, \mathrm{r}, \mathrm{s}), \\
& \mathrm{Cov}\left[\mathrm{G}(\lambda), \mathrm{u}^{\prime}(\mathrm{S}+\mathrm{G}(\lambda))\right]=\mathrm{K}_{1} \gamma(\mathrm{Sc})^{2} \cdot \mathrm{J}(2(\mathrm{~N}-1) \\
& +1, \gamma \mathrm{Sc}, \mathrm{r}, \mathrm{s}) .
\end{aligned}
$$

Proceeding now as in Example 2.1, it is possible to determine numerically the corresponding truncated exponential utility prices and the optimal proportions in (2.1).
3. Mean-variance efficiency of the optimal utility portfolios: It is worthwhile and instructive to compare portfolio selection under utility pricing with the classical mean-variance portfolio selection. Let the set $\mathrm{W}=\left\{\mathrm{W} \mid \sum_{\mathrm{j}=1}^{\mathrm{n}} \mathrm{w}_{\mathrm{j}}=1\right\}$ describe all portfolio choices.

Recall that a portfolio $\bar{w} \in W$ belongs to the meanvariance boundary if and only if, for some $\bar{\mu}$, the portfolio $\overline{\mathrm{w}}$ solves the problem $\min _{\mathrm{w} \in \mathrm{W}}\left\{\sigma_{\mathrm{w}}^{2}=\mathrm{w}^{\mathrm{T}} \mathrm{Vw}\right\}$ subject to $\mu_{\mathrm{w}}=\mathrm{w}^{\mathrm{T}} \cdot \mathrm{e}=\bar{\mu}$. A portfolio $\mathrm{w} \in \mathrm{W}$ belongs to the mean-variance efficient frontier if and only if no portfolio $v \in W$ exists such that $\mu_{\mathrm{v}} \geq \mu_{\mathrm{w}}$ and $\sigma_{\mathrm{v}} \leq \sigma_{\mathrm{w}}$, where at least one of the inequalities is strict.

From Merton ${ }^{[15]}$ or Huang and Litzenberger ${ }^{[2]}$, one knows that a portfolio $w$ belongs to the mean-variance boundary if and only if

$w=g+h \cdot \bar{\mu}$,

where $g$ and $h$ are the vectors defined by

$$
\begin{aligned}
& \mathrm{g}=\frac{1}{\mathrm{D}}\left[\mathrm{B}\left(\mathrm{V}^{-1} \mathrm{e}^{\mathrm{T}}\right)-\mathrm{A}\left(\mathrm{V}^{-1} \mu^{\mathrm{T}}\right)\right], \\
& \mathrm{h}=\frac{1}{\mathrm{D}}\left[\mathrm{C}\left(\mathrm{V}^{-1} \mu^{\mathrm{T}}\right)-\mathrm{A}\left(\mathrm{V}^{-1} \mathrm{e}^{\mathrm{T}}\right)\right]
\end{aligned}
$$

with

$$
\begin{array}{ll}
\mathrm{A}=\overline{1}^{\mathrm{T}} \cdot\left(\mathrm{V}^{-1} \mathrm{e}\right), & \mathrm{B}=\mathrm{e}^{\mathrm{T}} \cdot\left(\mathrm{V}^{-1} \mathrm{e}\right), \\
\mathrm{C}=\overline{1}^{\mathrm{T}} \cdot\left(\mathrm{V}^{-1} \frac{1}{1}\right), & \mathrm{D}=\mathrm{BC}-\mathrm{A}^{2} .
\end{array}
$$

The mean-variance efficient frontier consists of those weight vectors (3.1) for which $\bar{\mu} \geq \frac{\mathrm{A}}{\mathrm{C}}$. It is remarkable that the optimal portfolios (2.9), (2.16) and (2.23) are all equal and belong to the mean-variance efficient frontier.

Theorem 3.1: The optimal quadratic utility portfolio, the optimal exponential utility portfolio and the optimal elliptical portfolio coincide and are mean-variance efficient.

Proof: The expected return of the optimal exponential utility portfolio is $\mu^{\mathrm{o}}=\mathrm{e}^{\mathrm{T}} \cdot \mathrm{w}^{\mathrm{o}}=\frac{\mathrm{e}^{\mathrm{T}} \cdot\left(\mathrm{V}^{-1} \mathrm{e}\right)}{\mathrm{A}}=\frac{\mathrm{B}}{\mathrm{A}}$. Using (3.1) and (3.2) one obtains immediately that $\mathrm{g}+\mathrm{h} \cdot \mu^{\mathrm{o}}=\frac{\mathrm{V}^{-1} \mathrm{e}}{\mathrm{A}}$, which by (3.1) shows that $w^{o}$ belongs to the mean-variance boundary. Since $\mu^{\circ}=\frac{\mathrm{B}}{\mathrm{A}}>\frac{\mathrm{A}}{\mathrm{C}}$ (because $\mathrm{D}=\mathrm{BC}-\mathrm{A}^{2}>0$ ) the portfolio is mean-variance efficient. Since (2.23) is identical to (2.16), it remains to show that (2.9) and (2.16) yield the same optimal portfolios. Let $\wp$ and $w$ denote the optimal portfolios defined by (2.9) and (2.16). To obtain them, one solves the linear systems $V^{0} Q 0=\mathrm{e}$, 
$\mathrm{Vx}=\mathrm{e} \quad$ and $\quad$ set $\quad \stackrel{Q}{\%}=\frac{\mathscr{Q}_{0}}{\overline{1}^{\mathrm{T}} \cdot \mathrm{X}_{0}}, \quad \mathrm{w}=\frac{\mathrm{x}}{\overline{1}^{\mathrm{T}} \cdot \mathrm{x}}$. Since $V_{0}=\mathrm{V}+\mathrm{M}$ with $\mathrm{M}=\left(\mu_{\mathrm{i}} \mu_{\mathrm{j}}\right)$, one sees immediately that the equation $\widetilde{V} \widetilde{x}=e$ is equivalent to the equation $\mathrm{V} \mathscr{\mathrm { X }} \sigma=\left(1-\mathrm{e}^{\mathrm{T}} \mathrm{X}\right) \cdot \mathrm{e}$. But $\mathrm{e}^{\mathrm{T}} \mathrm{X} \sigma=\mathrm{e}^{\mathrm{T}}\left(\mathrm{V}^{\mathrm{O}} \overline{0}^{1} \mathrm{e}\right)=\mathrm{B}^{0}$ is a constant. It follows that $W_{0}=\frac{\mathscr{Q}_{0}}{\overline{1}^{\mathrm{T}} \cdot \mathrm{Q}_{0}}=\frac{(1-\mathrm{B})\left(\mathrm{V}^{-1} \mathrm{e}\right)}{\overline{1}^{\mathrm{T}} \cdot\left(1-\mathrm{B}^{\circ}\right)\left(\mathrm{V}^{-1} \mathrm{e}\right)}=\frac{\mathrm{V}^{-1} \mathrm{e}}{\mathrm{A}}=\mathrm{w}$, which shows the assertion.

In view of the present unification result, the portfolio defined by the weight vector $\mathrm{w}^{\circ}=\frac{\mathrm{V}^{-1} \mathrm{e}}{\mathrm{A}}$ will simply be called optimal utility portfolio. As an additional property, it is important to observe that any mean-variance efficient portfolio $w \neq w^{o}$ is nonoptimal in the following sense. For any such $w$, investing the amount $S$ yields by construction a terminal random wealth, whose corresponding expected utility satisfies the inequality $\mathrm{E}[\mathrm{u}(\mathrm{S}+\mathrm{G}(\lambda))] \leq \mathrm{E}\left[\mathrm{u}\left(\mathrm{S}+\mathrm{G}\left(\lambda^{\mathrm{o}}\right)\right)\right]$, where $\lambda^{\mathrm{o}}$ is the optimal proportion vector defined in (2.1). In the very narrow sense of maximizing this expected utility, the optimal utility portfolio is the preferred mean-variance efficient portfolio choice.

\section{Some properties of the optimal utility portfolio:}

Given the optimal utility portfolio $w=\frac{V^{-1} e}{A}$, which maximizes the expected utility of the terminal random wealth under various assumptions, it appears useful to study the behavior of this particular solution with respect to some typical situations.

In the special case $n=2$, often used as illustration, we use the notations $R_{X}, R_{Y}$ for the random returns instead of $R_{1}, R_{2}$. Assume that the bivariate distributed returns have means $\mu_{\mathrm{X}}, \mu_{\mathrm{Y}}$, standard deviations $\sigma_{\mathrm{X}}, \sigma_{\mathrm{Y}}$ and correlation coefficient $\rho$. The coefficients of variation are denoted $k_{X}=\frac{\sigma_{X}}{\mu_{X}}, k_{Y}=\frac{\sigma_{Y}}{\mu_{Y}}$.

Question 1: When is complete diversification optimal?

In case some of each risky asset is purchased, that is $\mathrm{w}_{\mathrm{i}}>0$ for all $\mathrm{i} \in\{1, \ldots, \mathrm{n}\}$, one speaks of complete diversification ${ }^{[16-18]}$. This situation occurs if and only if $\mathrm{V}^{-1} \mathrm{e}>0$ (each vector component is strictly positive). For example, if $n=2$ one has

$$
\mathrm{V}^{-1} \mathrm{e}=\frac{1}{\left(1-\rho^{2}\right) \sigma_{\mathrm{X}}^{2} \sigma_{\mathrm{Y}}^{2}} \cdot\left(\begin{array}{c}
\sigma_{\mathrm{Y}}^{2} \mu_{\mathrm{X}}-\rho \sigma_{\mathrm{X}} \sigma_{\mathrm{Y}} \mu_{\mathrm{Y}} \\
\sigma_{\mathrm{X}}^{2} \mu_{\mathrm{Y}}-\rho \sigma_{\mathrm{X}} \sigma_{\mathrm{Y}} \mu_{\mathrm{X}}
\end{array}\right)>0
$$

if and only if $\rho<\min \left\{\frac{\mathrm{k}_{\mathrm{Y}}}{\mathrm{k}_{\mathrm{X}}}, \frac{\mathrm{k}_{\mathrm{X}}}{\mathrm{k}_{\mathrm{Y}}}\right\}$ or equivalently

$$
\operatorname{Cov}\left[\frac{\mathrm{R}_{\mathrm{X}}}{\mu_{\mathrm{X}}}, \frac{\mathrm{R}_{\mathrm{Y}}}{\mu_{\mathrm{Y}}}\right]<\min \left\{\operatorname{Var}\left[\frac{\mathrm{R}_{\mathrm{X}}}{\mu_{\mathrm{X}}}\right], \operatorname{Var}\left[\frac{\mathrm{R}_{\mathrm{Y}}}{\mu_{\mathrm{Y}}}\right]\right\} \text {. }
$$

In particular, this situation allows for positively correlated returns, which are typically observed in financial markets and whose financial risk cannot be eliminated through diversification ${ }^{[19]}$.

Question 2: How does the optimal portfolio behave under univariate ordering of risks?

In general, let $\mathrm{R}^{(\mathrm{i})}=\left(\mathrm{R}_{1}^{(\mathrm{i})}, \ldots, \mathrm{R}_{\mathrm{n}}^{(\mathrm{i})}\right), \mathrm{i}=1,2$, be two vectors of multivariate normally distributed returns and let $\mathrm{w}^{(\mathrm{i})}, \mathrm{i}=1,2$, the corresponding optimal portfolios. The random returns of the optimal portfolios are denoted here $\mathrm{R}_{\mathrm{i}}=\left[\mathrm{W}^{(\mathrm{i})}\right]^{\mathrm{T}} \cdot \mathrm{R}^{(\mathrm{i})}, \mathrm{i}=1,2$. Comparing their expected exponential utilities, one knows from standard ordering of risks theory ${ }^{[20]}$ that

$\mathrm{E}\left[\mathrm{u}\left(\mathrm{R}_{1}\right)\right] \leq \mathrm{E}\left[\mathrm{u}\left(\mathrm{R}_{2}\right)\right]$

if and only if

$R_{1} \leq_{s l} R_{2}$

where $\leq_{s l}$ denotes the stop-loss order or equivalently the increasing convex order. Under normally distributed returns, the relation (4.4) holds if and only if the means and standard deviations are ordered as follows:

$\mu_{1} \leq \mu_{2}, \quad \sigma_{1} \leq \sigma_{2}$.

From the proof of Theorem 3.1, one knows that $\mu_{i}=\frac{B_{i}}{A_{i}}, i=1,2$, where the constants $\mathrm{A}_{\mathrm{i}}, \mathrm{B}_{\mathrm{i}}$ are defined as in (3.3). Using Huang and Litzenberger ${ }^{[2]}$, formula (3.11.2b), one obtains further

$\sigma_{\mathrm{i}}^{2}=\frac{1}{\mathrm{D}_{\mathrm{i}}}\left(\mathrm{C}_{\mathrm{i}} \cdot \mu_{\mathrm{i}}^{2}-2 \mathrm{~A}_{\mathrm{i}} \cdot \mu_{\mathrm{i}}+\mathrm{B}_{\mathrm{i}}\right)=\frac{\mathrm{B}_{\mathrm{i}}}{\mathrm{A}_{\mathrm{i}}^{2}}, \quad \mathrm{i}=1,2$.

These results allow for a numerical evaluation of the criterion (4.5), which is left to the interested reader.

Question 3: How does the optimal portfolio behave under multivariate ordering of risks?

Given some multivariate ordering of relative riskiness between the two vectors $R^{(1)}$ and $R^{(2)}$, how do the corresponding optimal weight vectors $W^{(1)}$ and $W^{(2)}$ behave? This difficult question has only been scarcely discussed in the literature. For similar but different portfolio selection problems, one finds some results in the studies by Fishburn and Porter ${ }^{[21]}$, Landsberger and Meilijson $^{[22]}$, Eeckhoudt and Gollier ${ }^{[24]}$, Hürlimann ${ }^{[18]}$. To illustrate, let us restrict our attention to the bivariate situation $n=2$ and let us assume that the normally distributed pairs $\left(\mathrm{R}_{\mathrm{X}}^{(1)}, \mathrm{R}_{\mathrm{Y}}^{(1)}\right)$ and $\left(\mathrm{R}_{\mathrm{X}}^{(2)}, \mathrm{R}_{\mathrm{Y}}^{(2)}\right)$ have equal margins, in particular equal means $\mu_{\mathrm{X}}, \mu_{\mathrm{Y}}$, equal 
standard deviations $\sigma_{\mathrm{X}}, \sigma_{\mathrm{Y}}$, but different correlation coefficients $p^{(1)}$ and $p^{(2)}$. We assume that the second return is more risky than the first in the sense that the coefficients of variation satisfy the inequality $\mathrm{k}_{\mathrm{Y}}>\mathrm{k}_{\mathrm{X}}$. What happens under the correlation order of riskiness $\left(\mathrm{R}_{\mathrm{X}}^{(1)}, \mathrm{R}_{\mathrm{Y}}^{(1)}\right) \leq_{\mathrm{c}}\left(\mathrm{R}_{\mathrm{X}}^{(2)}, \mathrm{R}_{\mathrm{Y}}^{(2)}\right)$ ? This main bivariate ordering of risks has been considered among others in Yanagimoto and Okamoto ${ }^{[23]}$, Cambanis et al. ${ }^{[25]}$, Tchen $^{[26]}$, Dhaene and Goovaerts ${ }^{[27]}$. In our special bivariate situation, the above relation holds exactly when $\rho^{(1)} \leq \rho^{(2)}$. Now, the weights in the more risky asset are given by

$$
\mathrm{w}_{\mathrm{Y}}^{(\mathrm{i})}=\frac{1}{1+\frac{\mathrm{k}_{\mathrm{Y}}^{2}-\rho^{(\mathrm{i})} \mathrm{k}_{\mathrm{X}} \mathrm{k}_{\mathrm{Y}}}{\mathrm{k}_{\mathrm{X}}^{2}-\rho^{(\mathrm{i})} \mathrm{k}_{\mathrm{X}} \mathrm{k}_{\mathrm{Y}}} \cdot \frac{\mu_{\mathrm{Y}}}{\mu_{\mathrm{X}}}}, \quad \mathrm{i}=1,2 .
$$

It is immediate that $\rho^{(1)} \leq \rho^{(2)}$ and $\mathrm{k}_{\mathrm{Y}}>\mathrm{k}_{\mathrm{X}}$ implies $\mathrm{w}_{\mathrm{Y}}^{(2)} \leq \mathrm{w}_{\mathrm{Y}}^{(1)}$. This means that a decision maker will proportionally invest more in the riskier asset of the less correlated risky pair. This induces a preference relation for low dependence between returns, which seems to be in accordance with the usual standards in modern finance.

Question 4: How does the optimal portfolio behave under risk-adjusted performance measurement?

A modern investor decides upon investment by looking at the tradeoff between expected return and risk, where risk is measured using a so-called coherent measure of risk ${ }^{[28]}$. A simple and popular coherent measure of risk, at least since Rockafellar and Uryasev $^{[29]}$, is conditional value-at-risk to some confidence level $\alpha$, which for a normally distributed random return $R$ equals

$\mathrm{CVaR}_{\alpha}[-\mathrm{R}]=\mathrm{E}\left[-\mathrm{R} \mid-\mathrm{R}>\operatorname{VaR}_{\alpha}[-\mathrm{R}]\right]$

$=\frac{1}{1-\alpha} \varphi\left[\Phi^{-1}(\alpha)\right] \cdot \sigma-\mu$,

where $\operatorname{VaR}_{\alpha}[-\mathrm{R}]=\inf \{\mathrm{x} \mid \operatorname{Pr}(\mathrm{R} \geq-\mathrm{x}) \geq \alpha\}$ is the value-atrisk, $\Phi(\mathrm{x})$ is the standard normal distribution, $\varphi(\mathrm{x})=\Phi^{\prime}(\mathrm{x})$ and $\mu, \sigma$ are the mean and standard deviation of $R$. For risk-adjusted performance measurement, one looks at the random return per unit of conditional value-at-risk to a fixed confidence level $\alpha$, called CVaR return ratio, which is defined by

$$
\frac{\mathrm{R}}{\mathrm{CVaR}_{\alpha}[-\mathrm{R}]}
$$

The expected value of the $\mathrm{CVaR}$ return ratio measures the risk-adjusted return on capital. This way of computing the return is commonly called RAROC ${ }^{[30]}$ and is defined by

$\operatorname{RAROC}_{\alpha}[\mathrm{R}]=\frac{\mathrm{E}[\mathrm{R}]}{\mathrm{CVaR}_{\alpha}[-\mathrm{R}]}$
Now, if an investor has to decide upon the more profitable of two optimal portfolios with random returns $R_{1}$ and $R_{2}$, a decision in favor of the second return is taken if and only if one has $\operatorname{RAROC}_{\alpha}\left[\mathrm{R}_{2}\right] \geq \operatorname{RAROC}_{\alpha}\left[\mathrm{R}_{1}\right]$ at given confidence levels $a$. This preference criterion tells us that a return is preferred to another if its expected value per unit of economic risk capital is greater. By (4.8) and the results for Question 2, one obtains the chain of equivalent inequalities

$\operatorname{RAROC}_{\alpha}\left[\mathrm{R}_{2}\right] \geq$ RAROC $_{\alpha}\left[\mathrm{R}_{1}\right] \Leftrightarrow$
$\mathrm{k}_{2}=\frac{\sigma_{2}}{\mu_{2}}=\frac{1}{\sqrt{\mathrm{B}_{2}}} \leq \mathrm{k}_{1}=\frac{\sigma_{1}}{\mu_{1}}=\frac{1}{\sqrt{\mathrm{B}_{1}}} \Leftrightarrow$
$\mathrm{B}_{1} \leq \mathrm{B}_{2}$.

Appendix A: A variant of Stein's Lemma

Theorem A.1: Let $(X, Y)$ be a bivariate real random vector with distribution $\mathrm{F}_{(\mathrm{X}, \mathrm{Y})}(\mathrm{x}, \mathrm{y})$ and let $g(x)$ be a real differentiable function such that $\lim _{\mathrm{x} \rightarrow-\infty} \mathrm{g}(\mathrm{x})=0$.

Suppose $(X, Y)$ satisfies the linear regression property (LR) $\mathrm{E}[\mathrm{X} \mid \mathrm{Y}=\mathrm{y}]=\mathrm{E}[\mathrm{X}]+\beta \cdot(\mathrm{y}-\mathrm{E}[\mathrm{Y}])$,

Where $\beta=\beta[X, Y]$ is some constant depending on $(X, Y)$. Then one has the identity

$\operatorname{Cov}[\mathrm{X}, \mathrm{g}(\mathrm{Y})]=\beta \cdot \operatorname{Cov}[\mathrm{Y}, \mathrm{g}(\mathrm{Y})]$

Proof: First, integrate both sides of (LR) with respect to the conditional distribution $F_{Y}(\cdot \mid Y \leq y)$ to get the identity

$\mathrm{E}[\mathrm{X}]-\mathrm{E}[\mathrm{X} \mid \mathrm{Y} \leq \mathrm{y}]=\beta \cdot\{\mathrm{E}[\mathrm{Y}]-\mathrm{E}[\mathrm{Y} \mid \mathrm{Y} \leq \mathrm{y}]\}$

The covariance formula by Hoeffding ${ }^{[31]}$ (or Lehmann $^{[32]}$, Lemma 2) yields

$\operatorname{Cov}[\mathrm{X}, \mathrm{g}(\mathrm{Y})]=\int_{-\infty}^{\infty} \int_{-\infty}^{\infty}\left\{\mathrm{F}_{\mathrm{X}, \mathrm{Y}}(\mathrm{x}, \mathrm{y})-\mathrm{F}_{\mathrm{X}}(\mathrm{x}) \mathrm{F}_{\mathrm{Y}}(\mathrm{y})\right\} \mathrm{g}^{\prime}(\mathrm{y}) \mathrm{dxdy}$

$=\int_{-\infty}^{\infty} \int_{-\infty}^{\infty}\left\{F_{X}(x \mid Y \leq y)-F_{X}(x)\right\} F_{Y}(y) g^{\prime}(y) d x d y$

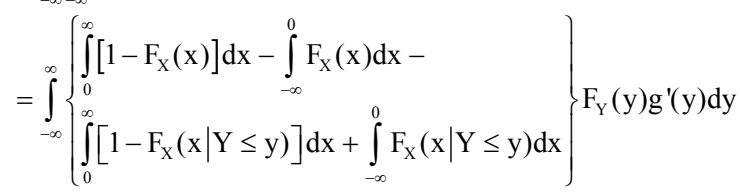

$=\int\{E[X]-E[X \mid Y \leq y]\} F_{Y}(y) g^{\prime}(y) d y$.

Inserting (A.2) one gets

$\operatorname{Cov}[\mathrm{X}, \mathrm{g}(\mathrm{Y})]=\beta \cdot \int_{-\infty}^{\infty} \mathrm{I}(\mathrm{y}) \mathrm{g}^{\prime}(\mathrm{y}) \mathrm{dy}$, with

$\mathrm{I}(\mathrm{y})=\{\mathrm{E}[\mathrm{Y}]-\mathrm{E}[\mathrm{Y} \mid \mathrm{Y} \leq \mathrm{y}]\} \mathrm{F}_{\mathrm{Y}}(\mathrm{y})$

$=\int_{-\infty}^{\mathrm{y}}(\mathrm{E}[\mathrm{Y}]-\mathrm{t}) \mathrm{dy}=\int_{\mathrm{y}}^{\infty}(\mathrm{t}-\mathrm{E}[\mathrm{Y}]) \mathrm{dy}$

Inserting (A.4) into (A.3) and applying Fubini's theorem as well as the assumption $\lim _{\mathrm{x} \rightarrow-\infty} \mathrm{g}(\mathrm{x})=0$, one obtains furthermore 
$\int_{-\infty}^{\infty} I(y) g^{\prime}(y) d y=\int_{-\infty}^{\infty}\left\{\int_{y}^{\infty}(t-E[Y]) d F_{Y}(t)\right\} g^{\prime}(y) d y$

$=\int_{-\infty}^{\infty}\left\{\int_{-\infty}^{t} g^{\prime}(y) d y\right\}(t-E[Y]) d F_{Y}(t)=\int_{-\infty}^{\infty}(t-E[Y]) g(t) d F_{Y}(t)$

$=\mathrm{E}[(\mathrm{Y}-\mathrm{E}[\mathrm{Y}]) \cdot \mathrm{g}(\mathrm{Y})]=\operatorname{Cov}[\mathrm{Y}, \mathrm{g}(\mathrm{Y})]$,

Which shows the desired identity.

In the special case of a bivariate normal random vector, one has $\beta=\frac{\operatorname{Cov}[\mathrm{X}, \mathrm{Y}]}{\operatorname{Var}[\mathrm{Y}]}$ and the identity ${ }^{[33]}$ Lemma 2.2

$\operatorname{Cov}[\mathrm{Y}, \mathrm{g}(\mathrm{Y})]=\mathrm{E}\left[\mathrm{g}^{\prime}(\mathrm{Y})\right] \cdot \operatorname{Var}[\mathrm{Y}]$,

which implies the relationship

$\operatorname{Cov}[\mathrm{X}, \mathrm{g}(\mathrm{Y})]=\mathrm{E}\left[\mathrm{g}^{\prime}(\mathrm{Y})\right] \cdot \operatorname{Cov}[\mathrm{X}, \mathrm{Y}]$,

In the literature this is attributed to Stein ${ }^{[34,35]}$, Huang and Litzenberger ${ }^{[2]}$. Since a lot of bivariate random models satisfy the required linear regression property, the displayed covariance identity has a wide application. Among the many multivariate models satisfying linear regression properties, let us mention the following few but important classes and families of multivariate distributions:

* The class of symmetric elliptical distributions ${ }^{[3]}$

* Bivariate and multivariate distributions of Pearson type $^{[36,37]}$

* Bivariate and multivariate Pareto distributions of the first kind ${ }^{[38]}$

* Bivariate and multivariate distributions constructed from linear Spearman or Fréchet copulas with margins from location-scale families ${ }^{[11,12,37,39]}$

Appendix B: Numerical evaluation of two special integral functions

First, we show how to compute the integral (2.30), that is

$\mathrm{I}=\mathrm{I}(\mathrm{a}, \mathrm{b})=\int_{0}^{\infty}\left(1+\mathrm{x}^{2}\right)^{-\mathrm{a}} \mathrm{e}^{-\mathrm{bx}} \mathrm{dx}$

Divide the integral into two parts such that $I=I_{1}+I_{2}$ with

$I_{1}=\int_{0}^{1}\left(1+x^{2}\right)^{-a} e^{-b x} d x$

$\mathrm{I}_{2}=\int_{1}^{\infty}\left(1+\mathrm{x}^{2}\right)^{-\mathrm{a}} \mathrm{e}^{-\mathrm{bx}} \mathrm{dx}$

Recall the binomial series expansion

$$
\begin{aligned}
& (1+\mathrm{z})^{\alpha}=\sum_{\mathrm{k}=0}^{\infty}\left(\begin{array}{l}
\alpha \\
\mathrm{k}
\end{array}\right) \mathrm{z}^{\mathrm{k}}, \quad|\mathrm{z}|<1, \quad\left(\begin{array}{l}
\alpha \\
\mathrm{k}
\end{array}\right) \\
& =\frac{\alpha(\alpha-1) \ldots(\alpha-\mathrm{k}+1)}{\mathrm{k} !}
\end{aligned}
$$

which is valid for all real numbers $\alpha$. Inserted into (B.2) one obtains

$$
\begin{aligned}
& \mathrm{I}_{1}=\sum_{\mathrm{k}=0}^{\infty}\left(\begin{array}{c}
-\mathrm{a} \\
\mathrm{k}
\end{array}\right) \cdot \int_{0}^{1} \mathrm{x}^{2 \mathrm{k}} \mathrm{e}^{-\mathrm{bx}} \mathrm{dx} \\
& =\sum_{\mathrm{k}=0}^{\infty}\left(\begin{array}{c}
-\mathrm{a} \\
\mathrm{k}
\end{array}\right) \cdot \frac{\Gamma(2 \mathrm{k}+1)}{\mathrm{b}^{2 \mathrm{k}+1}} \mathrm{G}(\mathrm{b} ; 2 \mathrm{k}+1)
\end{aligned}
$$

where $\mathrm{G}(\mathrm{x} ; \alpha)=\Gamma(\alpha)^{-1} \cdot \int_{0}^{\mathrm{x}} \mathrm{t}^{\alpha-1} \mathrm{e}^{-\mathrm{t}} \mathrm{dt}$ denotes the incomplete gamma function. For (B.3) note that $\left(1+x^{2}\right)^{-a}=x^{2 a} \cdot\left(1+x^{-2}\right)^{-a}$ and apply (B.4) on the second term. One obtains

$$
\mathrm{I}_{2}=\sum_{\mathrm{k}=0}^{\infty}\left(\begin{array}{c}
-\mathrm{a} \\
\mathrm{k}
\end{array}\right) \cdot \mathrm{J}_{\mathrm{k}}, \quad \mathrm{J}_{\mathrm{k}}=\int_{1}^{\infty} \mathrm{x}^{2 \mathrm{a}-2 \mathrm{k}} \mathrm{e}^{-\mathrm{bx}} \mathrm{dx},
$$

where the integrals can be calculated recursively as follows (use partial integration) :

$$
\begin{aligned}
\mathrm{J}_{\mathrm{k}} & =\frac{1}{2 \mathrm{a}-2 \mathrm{k}+1}\left[\frac{\mathrm{b}}{2 \mathrm{a}-2 \mathrm{k}+2}\left(\mathrm{bJ}_{\mathrm{k}-1}-\mathrm{e}^{-\mathrm{b}}\right)-\mathrm{e}^{-\mathrm{b}}\right], \\
\mathrm{k} & \geq 1, \mathrm{~J}_{0}=\frac{\Gamma(2 \mathrm{a}+1)}{\mathrm{b}^{2 \mathrm{a}+1}}[1-\mathrm{G}(\mathrm{b} ; 2 \mathrm{a}+1)] .
\end{aligned}
$$

The evaluation of the second special integral (2.39) is simpler. Using the exponential series $\exp \left(-\mathrm{rz}^{2 \mathrm{~s}}\right)=\sum_{\mathrm{k}=0}^{\infty} \frac{(-1)^{\mathrm{k}} \mathrm{r}^{\mathrm{k}}}{\mathrm{k} !} \mathrm{z}^{2 \mathrm{ks}}$, one obtains the Gamma function series expansion

$$
\begin{aligned}
& J(a, b, r, s)=\frac{1}{b} \cdot \int_{0}^{\infty} x^{a} e^{-r x^{2 s}-b x} d x \\
& =\sum_{k=0}^{\infty} \frac{(-1)^{k} r^{k}}{k !} \cdot \frac{\Gamma(a+2 k s+1)}{b^{a+2 k s+1}} .
\end{aligned}
$$

\section{REFERENCES}

1. Markowitz, H.M., 1952. Portfolio selection. The J. Finance, pp: 77-91.

2. Huang, C. and R.H. Litzenberger, 1988. Foundations for Financial Economics. Elsevier Science Publishing Company.

3. Fang, K.-T., S. Kotz and K.-W. Ng, 1990. Symmetric Multivariate and Related Distributions. Chapman and Hall.

4. Hogg, R. and S. Klugman, 1984. Loss Distributions. John Wiley. New York.

5. Heilmann, W.-R., 1989. Decision theoretic foundations of credibility theory. Insurance: Mathematics and Economics, 8: 77-95.

6. Johnson, N.L., A. Kotz and N. Balakrishnan, 1995. Continuous Univariate Distributions. (2nd Edn.). John Wiley, New York.

7. Praetz, P.D., 1972. The distribution of share price changes. J. Business, 45: 49-65.

8. Blattberg, R.C. and N.J. Gonedes, 1974. A comparison of the stable and Student distributions as statistical models for stock prices. J. Business, 47: 244-80.

9. Kon, S.J., 1984. Models of stock returns - A comparison. J. Finance, 39: 147-65.

10. Taylor, S.J., 1992. Modeling Financial Time Series. (3rd reprint). John Wiley.

11. Hürlimann, W., 2001a. Financial data analysis with two symmetric distributions. ASTIN Bulletin, 31: $187-211$. 
12. Hürlimann, W., 2004a. Fitting bivariate cumulative returns with copulas. Computational Statistics and Data Analysis, 45: 355-372.

13. Hürlimann, W., 1995. Predictive stop-loss premiums and Student's t-distribution. Insurance: Mathematics and Economics, 16: 151-59.

14. Kotz, S., 1975. Multivariate distributions at a cross-road. In Patil, G.P., Kotz S. and J.K. Ord (Eds.). Statistical Distributions in Scientific Work, 1. D. Reidel Publ. Co.

15. Merton, R., 1972. An analytical derivation of the efficient portfolio frontier. J. Financial and Quant. Analysis, 7: 1851-72.

16. Samuelson, P.A., 1967. General proof that diversification pays. J. Finance and Quant. Analysis, 2: 1-13. Reprinted in Merton, R.C. 1972, Vol. 3.

17. Wright, R., 1987. Expectation dependence of random variables, with an application in portfolio theory. Theory and Decision, 22: 111-124.

18. Hürlimann, W., 2000. On a classical portfolio problem: Diversification, comparative static and other issues. Proceedings of the 10th Intl. AFIR Colloquium, Norway.

19. Sharpe, W.F., 1985. Investments. Prentice-Hall International. 3rd Edn.

20. Kaas, R., Heerwaarden, van A.E. and M.J. Goovaerts, 1994. Ordering of Actuarial Risks. CAIRE Education Series 1, Brussels.

21. Fishburn, P. and B. Porter, 1976. Optimal portfolios with one safe and one risky asset: effects of changes in rate of return and risk. Management Sci., 22: 1069-1073.

22. Landsberger, M. and I. Meilijson, 1990. Demand for risky financial assets: A portfolio analysis. J. Economic Theory, 50: 204-213.

23. Eeckhoudt, L. and C. Gollier, 1995. Demand for risky assets and the monotone probability ratio order. J. Risk and Uncertainty, 11: 113-122.

24. Yanagimoto, T. and M. Okamoto, 1969. Partial orderings of permutations and monotonicity of a rank correlation statistic. Annals Institute of Statistical Mathematics, 21: 489-506.

25. Cambanis, S., G. Simons and W. Stout, 1976. Inequalities for $\mathrm{Ek}(\mathrm{X}, \mathrm{Y})$ when the marginals are fixed. Zeitschrift für Wahrscheinlichkeitstheorie und verw. Gebiete, 36: 285-294.
26. Tchen, A.H., 1980. Inequalities for distributions with given marginals. The Ann. Probab., 8: 814827.

27. Dhaene, J. and M.J. Goovaerts, 1996. Dependency of risks and stop-loss order. ASTIN Bulletin, 26: 201-212.

28. Artzner, P., F. Delbaen, J.M. Eber and D. Heath, 1999. Coherent measures of risk. Mathematical Finance, 9: 203-28.

29. Rockafellar, R.T. and S. Uryasev, 2002. Conditional value-at-risk for general loss distributions. Journal of Banking and Finance, 26: 1443-1476.

30. Matten, C., 1996. Managing Bank Capital. J. Wiley, Chichester.

31. Hoeffding, W., 1940. Massstabinvariante Korrelationstheorie. Schriften des Math. Instituts und des Instituts für Angewandte Mathematik der Universität Berlin, 5: 179-233. English translation in Fisher and Sen, 1994, pp: 57-107.

32. Lehmann, E.L., 1966. Some concepts of dependence. Ann. Math. Stat., 37: 1137-1153.

33. Haff, L.R. and R.W. Johnson, 1986. The superharmonic condition for simultaneous estimation of means in exponential families. Canadian J. Stat., 14: 43-54.

34. Stein, C.M., 1972. A bound for the error in the normal approximation to the distribution of a sum of dependent random variables. Proc. 6th Berkeley Symp. in Mathematical Statistics and Probability, 2: 583-602.

35. Stein, C.M., 1981. Estimation of the mean of a multivariate normal distribution. The Ann. Stat., 9: 1135-1151.

36. Johnson, N.L., A. Kotz and N. Balakrishnan, 2000. Continuous Multivariate Distributions, vol. 1. Models and Applications (2nd Edn.). John Wiley, New York.

37. Hürlimann, W., 2001b. An alternative approach to portfolio selection. Proc. of the 12th Intl. AFIR Colloquium, Cancun, Mexico.

38. Steyn, H.S., 1960. On regression properties of multivariate probability functions of Pearson's types. Proc. of the Royal Acad. of Sci., Amsterdam, 63: 302-311.

39. Hürlimann, W., 2004b. Multivariate Fréchet copulas and conditional value-at-risk. Intl. J. Math. and Math. Sci., 7: 345-364. 